Hall, A. V., Hall, E. V., \& Perry, J. L. (2016). Black and blue: Exploring racial bias and law enforcement in the killings of unarmed Black male civilians, American Psychologist, 71(3), 175-186.

Jost, J. T., \& Thompson, E. P. (2000). Group-based dominance and opposition to equality as independent predictors of self-esteem, ethnocentrism, and social policy attitudes among African Americans and European Americans. Journal of Experimental Social Psychology, 36, 209-232.

Kahn, K. B., \& Davies, P. G. (2011). Differentially dangerous? Phenotypic racial stereotypicality increases implicit bias among ingroup and outgroup members. Group Processes \& Intergroup Relations, 14(4), 569-580.

Matschke, C., \& Sassenberg, K. (2010). Does rejection lead to disidentification? The role of internal motivation and avoidance strategies. European Journal of Social Psychology, 40(6), 891-900.

Outten, H. R., Schmitt, M. T., Miller, D. A., \& Garcia, A. L. (2012). Feeling threatened about the future Whites' emotional reactions to anticipated ethnic demographic changes. Personality and Social Psychology Bulletin, 38(1), 14-25.

Overbeck, J. R., Jost, J. T., Mosso, C. O., \& Flizik, A. (2004). Resistant versus acquiescent responses to ingroup inferiority as a function of social dominance orientation in the USA and Italy. Group Processes \& Intergroup Relations, 7(1), 35-54.

Ruggs, E. N., Hebl, M. R., Rabelo, V. C., Weaver, K. B., Kovacs, J., \& Kemp, A. S. (2016). Baltimore is burning: Can I-O psychologists help extinguish the flames? Industrial and Organizational Psychology: Perspectives on Science and Practice, 9(3), 525-547.

Sidanius, J., Liu, J. H., Shaw, J. S., \& Pratto, F. (1994). Social dominance orientation, hierarchy attenuators and hierarchy enhancers: Social dominance theory and the criminal justice system. Journal of Applied Social Psychology, 24(4), 338-366.

Unzueta, M. M., Knowles, E. D., \& Ho, G. C. (2012). Diversity is what you want it to be how socialdominance motives affect construals of diversity. Psychological Science, 23(3), 303-309.

\title{
Theoretical Applications of the MODE Model to Law Enforcement Training and Interventions
}

\author{
Keith L. Zabel \\ Wayne State University \\ Kevin L. Zabel \\ Western New England University \\ Michael A. Olson \\ University of Tennessee \\ Jessica H. Carlson \\ Western New England University
}

Keith L. Zabel, Department of Psychology, Wayne State University; Kevin L. Zabel, Department of Psychology, Western New England University; Michael A. Olson, Department of Psychology, University of Tennessee; Jessica H. Carlson, Department of Psychology, Western New England University.

Correspondence concerning this article should be addressed to Keith L. Zabel, Department of Psychology, Wayne State University, 5057 Woodward Avenue, 7th Floor, Detroit, MI 48202. E-mail: keith.zabel@wayne.edu 
Table 1. Initiatives Based on the MODE Model to Reduce Racially Discriminatory Police Officer Behavior

\begin{tabular}{|c|c|c|}
\hline I-O focal area & Initiative & $\begin{array}{l}\text { Addresses motivation } \\
\text { or opportunity as } \\
\text { determinants? }\end{array}$ \\
\hline $\begin{array}{l}\text { Sensitivity } \\
\text { training/cultural } \\
\text { awareness }\end{array}$ & Awareness of racial biases & Motivation \\
\hline Performance management & Frequent performance feedback & Motivation \\
\hline Diversity training & $\begin{array}{l}\text { Inclusive environment/evaluative } \\
\text { priming }\end{array}$ & Motivation \\
\hline Positive intergroup contact & Potlucks, volunteer events & Motivation \\
\hline \multirow[t]{2}{*}{ Selection } & $\begin{array}{l}\text { Motivation to control prejudice as } \\
\text { selection device }\end{array}$ & Motivation \\
\hline & Cognitive ability as selection device & Opportunity \\
\hline Job analysis & $\begin{array}{l}\text { Identify situations where less lethal } \\
\text { weapons (e.g., Tasers) are effective }\end{array}$ & Opportunity \\
\hline Work/life balance & $\begin{array}{l}\text { Stress management } \\
\text { techniques/regular work schedules }\end{array}$ & Opportunity \\
\hline
\end{tabular}

Note. $\mathrm{I}-\mathrm{O}=$ industrial-organizational.

As discussed in the focal article, numerous research studies have supported the existence of automatic or implicit racial bias (Ruggs et al., 2016). In this commentary, we argue that examining implicit bias through the perspective of the motivation and opportunity as determinants (MODE) model (see Fazio \& Olson, 2014, for a review) offers a framework for industrialorganizational (I-O) psychologists to design and implement strategies that reduce the number of violent interactions between police and communities. The MODE model has been applied to areas such as interpersonal relationships (McNulty, Olson, Meltzer, \& Shaffer, 2013), effective treatment of mental disorders (Vasey, Harbaugh, Buffington, Jones, \& Fazio, 2012), and crafting of media messages (Ewoldsen, Rhodes, \& Fazio, 2015), as well as racial prejudice (Olson \& Fazio, 2004). Below, we elaborate on how the I-O-related strategies and interventions described in the focal article can be captured by the components of the MODE model and highlight which interventions may be most efficacious in reducing discriminatory police officer behavior. See Table 1 for a list of initiatives based on the MODE model to reduce racially discriminatory police officer behavior.

\section{I-O Strategies and Interventions Related to the MODE Model}

The MODE model specifies the processes by which automatically activated attitudes can guide behavior relatively spontaneously or through more 
deliberative processing. In many instances, racial attitudes are automatically activated upon perception of a minority individual and effortlessly influence behavior toward that minority (Fazio \& Olson, 2014). However, some behaviors are more carefully executed. Specifically, motivation and opportunity are posited to be determinants of the degree to which automatically activated racial attitudes predict behavior in an automatic, effortless manner. In the absence of either motivation (e.g., motivation to control prejudiced reactions, accuracy) or opportunity (i.e., time and cognitive resources), automatically activated racial attitudes are posited to directly predict behavior toward Black individuals. However, if sufficient motivation and opportunity exist, individuals can intercede on the otherwise direct influence that negative automatic racial attitudes exert on behavior and correct for the influence of those prejudices. Consistent with the MODE model, a substantial volume of research indicates that when both motivation and opportunity exist, individuals are able to correct for the otherwise negative influence that automatically activated racial attitudes have on behavior (see Fazio \& Olson, 2014, for a review).

We suggest that the strategies suggested by Ruggs et al. to "extinguish the flames" (p. 525) in Baltimore can be better understood by being couched in the dual-process terms articulated in the MODE model. Some strategies attempt to increase motivation to control automatic bias. Others aspire to increase opportunity to more carefully consider responses, whereas others attempt to reduce the automatic bias itself. For instance, training interventions such as sensitivity training and cultural awareness have been found to have a positive influence on behaviors (Kalinoski et al., 2013). From a MODE model perspective, these types of trainings are likely effective because they primarily increase police officers' motivation to control prejudice and may be less effective in reducing negative automatic racial attitudes themselves. Indeed, police officers still show an automatic shooter bias (albeit somewhat less than civilians do; Correll et al., 2007). A MODE model analysis affords researchers and practitioners' clarity on why such training is sometimes only partially effective or only effective in situations that afford an opportunity (e.g., time) to implement a more motivated rather than an automatic response.

From a MODE model perspective, ensuring performance management systems properly measure the effectiveness of police-community interactions should motivate police officers to have positive interactions with Blacks, which in turn should reduce the negative effect of the officers' implicit bias on behavior. Creating performance criteria that punish officers for discriminatory behavior, in tandem with frequent feedback data systems (e.g., body-mounted cameras, dash camera videos) and a greater sense of accountability should activate motives (i.e., motivation to control prejudiced reactions, responsibility) that have the potential to reduce the impact of 
automatic racial attitudes on behavior. In addition, proper performance criteria will enable officers and their leaders to set specific, measurable, achievable, realistic, and time-bound (SMART) goals that, if related to proper interracial interactions, should increase officers' motivation to reduce prejudice. Relatedly, initiatives (e.g., diversity training or having police officers take pledges against hate or intolerance) that create a police organizational environment free of racial jokes and that foster social norms that discourage disparaging actions (e.g., comments, racial profiling) toward African Americans should make officers more aware of the pernicious effects of their automatic racial attitudes. These initiatives should serve as important first steps to increasing motivation to control the effects of police officers' automatic racial attitudes. However, from the MODE model's perspective, motivation alone is not sufficient to disrupt the influence of automatic prejudice. These interventions fail to account for the degree to which opportunity (i.e., time and cognitive resources) exists in a given situation for a police officer to correct for the influence of their automatic biases. As discussed later in this commentary, although interventions that target opportunity are more difficult to implement, they are feasible and necessary for police officers to correct for the influence of their automatic racial attitudes.

\section{A MODE Model Perspective on the Role of Selection}

Of all the I-O psychology areas mentioned by Ruggs et al. as ways to resolve police-community conflict, employee selection may be the most fruitful avenue because it simultaneously allows for strategies to hire employees who lack negative automatic racial biases, have motivation to control prejudicial reactions, and have the opportunity (i.e., cognitive resources) to control for the influence of automatically activated attitudes. Well-validated measures of both automatic racial bias and motivation to control prejudice are readily available (see Olson \& Zabel, 2016, for a review). Their use as predictors in a selection framework have potential, because they should lead to selecting police officers who not only are motivated to control their prejudiced reactions but also are less apt to act negatively toward African Americans in lowopportunity circumstances. Furthermore, selection is one area in which the elusive factor of opportunity can be targeted. This is especially important, as the MODE model posits that both motivation and opportunity are necessary to control for the effect of implicit racial bias. Validating existing measures of working memory (Jaeggi, Buschkuehl, Perrig, \& Meier, 2010) as a predictor in a selection framework would allow for the selection of police officers who are more apt to have cognitive resources available in highly stressful circumstances and ergo the opportunity to correct for the influence of their automatic racial biases. 
When used in combination, a selection test that includes a battery of cognitive ability, working memory, automatic racial bias, and motivation to control prejudiced reactions measures should lead to selecting police officers who "fit the profile" of officers least likely to act in a discriminatory fashion. Because meta-analytic evidence suggests cognitive ability is the best predictor of future job performance (Hunter \& Hunter, 1984) but also leads to greater likelihood of adverse impact, this selection battery would need to be carefully constructed. Because the opportunity to correct for automatic prejudices is largely situationally dependent, reducing the very existence of negative automatic racial bias is the most guaranteed way to reduce the negative behavioral influences of automatic racial prejudice. An emphasis on getting diverse candidates into the recruiting pipeline should, at the least, increase the number of interracial interactions between officers and candidates, fostering an awareness of different perspectives that should increase officers' motivation to reduce prejudice. Leaders play a key role in implementing training, setting performance criteria, developing selection criteria, and fostering an inclusive organizational climate. Police departments would be wise to hire and develop leaders who are cognizant of automatic racial biases and devoted to eliminating their effects via empirically supported and theorized means.

\section{Suggestions for Expanded I-O Applications Based on the MODE Model}

From a MODE model perspective, shaping more positive automatically activated racial attitudes is the ultimate solution to reducing discriminatory behavior. Ample social psychology research already indicates that positive intergroup contact can reduce racial prejudices (e.g., Pettigrew, 1998). In this way, bridging the gap between police officers and the communities they serve should play an important role in reducing discriminatory police officer behavior. For instance, events such as potlucks in which police serve the community, picnics for members of the community and police officers, or volunteer events where police officers and community members work together for a common cause (e.g., building a playground) would provide opportunities for police officers to have positive intergroup contact with community members and meet Black exemplars incongruent with their negative automatic racial attitudes and stereotypes (e.g., Greene, 2000). These positive police-community interactions would not only increase motivation to control prejudiced reactions but also increase common goals and intergroup cooperation, two key ingredients in reducing negative intergroup attitudes (Pettigrew, 1998). Such interactions also help create more of a sense of "weness" and an inclusive social identity that includes both police officers and community members under the same umbrella. In this way, White police officers in predominantly African American communities may become more 
likely to think of police officers and community members as "one" working together for a common cause. Indeed, this type of common in-group identity has been found to reduce intergroup prejudices (Gaertner, Dovidio, Anastasio, Bachman, \& Rust, 1993). From the MODE model's perspective, these prejudice reduction approaches are effective particularly when they can reduce prejudice at the automatic level.

It is important to note that empirically supported research findings provide guidance for other means by which the factors of the MODE model might be influenced to curb discriminatory police officer behavior. For instance, evaluative conditioning in which Black faces were paired with positive words reduced negative automatic racial biases (Olson \& Fazio, 2006). Such techniques could not only be implemented as part of police officer diversity training and awareness but also be embedded within police officer training regarding the "Shooter Effect" paradigm (Correll, Hudson, Guillermo, \& Ma, 2014). Specifically, police officers could engage in a "shootor-not-shoot" task in which Black individuals frequently are unarmed. Over the period of training days, this frequent pairing may reduce the negative automatic activation of stereotypes and prejudices among police officers.

Finally, it must be recognized that opportunity (i.e., time and cognitive resources) to correct for the influence of automatic racial biases is situationally dependent and often absent in life-or-death situations that police officers may encounter. The understanding afforded by the MODE model-that motivation is impotent to correct for prejudice without opportunity-has the potential to influence policy initiatives. For instance, adopting the use of less lethal but effective weapons like Tasers may lead to fewer tragedies by mitigating the effects of officers' automatic bias in contexts in which officers lack the opportunity to correct for the influence of their automatic bias. I-O psychology techniques such as job analysis should help police departments determine situations and develop training plans for low-opportunity situations in which the use of Tasers is equally effective at eliminating a deadly threat as the use of deadly weapons. Furthermore, police leaders should create work schedules that do not overtax their officers cognitively (e.g., fewer double shifts), to allow officers the maximum amount of cognitive resources and opportunity to correct for the influence of their automatic racial biases. An emphasis on training appropriate stress management techniques and creating an environment that increases officers' engagement and perceived supervisor support may also increase officers' cognitive resources.

\section{Conclusions}

The MODE model is a useful framework for I-O psychologists to utilize in designing and applying interventions listed in the focal article and herein to reduce the effects of automatic racial bias in police departments. The MODE 
model makes specific predictions about the processes by which automatic attitudes predict behavior, as well as why and when interventions aimed at extinguishing the effects of automatic racial biases will be successful. We argue that police departments should be able to prevent discriminatory police officer behavior to the degree to which they are able to implement multifaceted interventions aimed at reducing automatic racial bias while increasing motivation to control prejudiced reactions, as well as providing a greater likelihood for their officers to be in contexts in which they have the opportunity to correct for the influence of their automatic racial biases. Theoretical grounding of I-O-related interventions and strategies allows for empirically validated techniques that have the maximum potential to "extinguish the flames" and reduce discriminatory police officer behavior stemming from automatic racial biases.

\section{References}

Correll, J., Hudson, S. M., Guillermo, S., \& Ma, D. S. (2014). The police officer's dilemma: A decade of research on racial bias in the decision to shoot. Social and Personality Psychology Compass, 8(5), 201-213. doi:10.1111/spc3.12099

Correll, J., Park, B., Judd, C. M., Wittenbrink, B., Sadler, M. S., \& Keesee, T. (2007). Across the thin blue line: Police officers and racial bias in the decision to shoot. Journal of Personality and Social Psychology, 92, 1006-1023. doi:10.1037/0022-3514.92.6.1006

Ewoldsen, D. R., Rhodes, N., \& Fazio, R. H. (2015). The MODE model and its implications for studying the media. Media Psychology, 18, 312-337. doi:10.1080/15213269.2014.937440

Fazio, R. H., \& Olson, M. A. (2014). The MODE model: Attitude-behavior processes as a function of motivation and opportunity. In J. W. Sherman, B. Gawronski, \& Y. Trope (Eds.), Dual process theories of the social mind (pp. 155-171). New York, NY: Guilford Press.

Gaertner, S. L., Dovidio, J. F., Anastasio, P. A., Bachman, B. A., \& Rust, M. C. (1993). The common ingroup identity model: Recategorization and the reduction of intergroup bias. European Review of Social Psychology, 4, 1-26. doi:10.1080/14792779343000004

Greene, J. R. (2000). Community policing in America: Changing the nature, structure, and function of the police. Criminal Justice, 3, 299-370.

Hunter, J. E., \& Hunter, R. F. (1984). Validity and utility of alternative predictors of job performance. Psychological Bulletin, 96, 72-98. doi:10.1037/0033-2909.96.1.72

Jaeggi, S. M., Buschkuehl, M., Perrig, W. J., \& Meier, B. (2010). The concurrent validity of the N-back task as a working memory measure. Memory, 18, 394-412. doi:10.1080/09658211003702171

Kalinoski, Z. T., Steele-Johnson, D., Peyton, E. J., Leas, K. A., Steinke, J., \& Bowling, N. A. (2013). A meta-analytic evaluation of diversity training outcomes. Journal of Organizational Behavior, 34, 1076-1104. doi:10.1002/job.1839

McNulty, J. K., Olson, M. A., Meltzer, A. L., \& Shaffer, M. J. (2013). Though they may be unaware, newlyweds implicitly know whether their marriage will be satisfying. Science, 342, 1119-1120. doi:10.1126/science. 1243140

Olson, M. A., \& Fazio, R. H. (2004). Trait inferences as a function of automatically activated racial attitudes and motivation to control prejudiced reactions. Basic and Applied Social Psychology, 26, 1-11. doi:10.1207/s15324834basp2601_1

Olson, M. A., \& Fazio, R. H. (2006). Reducing automatically activated racial prejudice through implicit evaluative conditioning. Personality and Social Psychology Bulletin, 32, 421-433. doi:10.1177/0146167205284004

Olson, M. A., \& Zabel, K. L. (2016). Measures of prejudice. In T. Nelson (Ed.), Handbook of prejudice, stereotyping, and discrimination (pp. 175-211). New York, NY: Psychology Press. 
Pettigrew, T.F. (1998). Intergroup contact theory. Annual Review of Psychology, 49, 65-85. doi:10.1146/annurev.psych.49.1.65

Ruggs, E. N., Hebl, M. R., Rabelo, V. C., Weaver, K. B., Kovacs, J., \& Kemp, A. S. (2016). Baltimore is burning: Can I-O psychologists help extinguish the flames? Industrial and Organizational Psychology: Perspectives on Science and Practice, 9(3), 525-547.

Vasey, M. W., Harbaugh, C. N., Buffington, A. G., Jones, C. R., \& Fazio, R. H. (2012). Predicting return of fear following exposure therapy with an implicit measure of attitudes. Behaviour Research and Therapy, 50, 767-774. doi:10.1016/j.brat.2012.08.007

\section{Additional Ideas for Putting Out the Flames}

Rick Jacobs, Jean Phillips, and Stan Gully

Pennsylvania State University

It is hard to argue with the central thesis of the focal article (Ruggs et al., 2016) that industrial-organizational (I-O) psychology has much to offer police departments in helping them meet their mission. As an example, the Los Angeles Police Department provides a clear statement that is representative of most police agencies:

\footnotetext{
It is the mission of the Los Angeles Police Department to safeguard the lives and property of the people we serve, to reduce the incidence and fear of crime, and to enhance public safety while working with the diverse communities to improve their quality of life. Our mandate is to do so with honor and integrity, while at all times conducting ourselves with the highest ethical standards to maintain public confidence. (Los Angeles Police Foundation \& LAPD, 2016)
}

The mission statement encompasses a wide range of responsibilities and associated tasks, competencies, and actions. Although much of what I-O psychology has accomplished over the past 100 years in the way of excellence in selection, training, performance management, leadership, and motivation can be directly linked to challenges these organizations face, it is a major undertaking to fit what we know into an integrated set of programs that can not only help departments succeed but also simultaneously help them avoid tragedies. Highly visible examples of police misconduct from across the country have filled the news media. The deaths of Freddie Gray (Baltimore, MD), Michael Brown, Jr. (Ferguson, MO), Eric Garner (Staten Island, NY), Laquan McDonald (Chicago, IL), and unfortunately many more represent isolated but extreme problems in implementing the police mission. In reading "Baltimore Is Burning," four questions emerged and should be

Rick Jacobs, Department of Psychology, Pennsylvania State University; Jean Phillips and Stan Gully, School of Labor and Employment Relations, Pennsylvania State University.

Correspondence concerning this article should be addressed to Rick Jacobs, Department of Psychology, Pennsylvania State University, University Park, PA 16802. E-mail: rick.jacobs@ebjacobs.com 